\title{
Effects of mixtures containing chlordecone and a dechlorinated by-product on hydra regeneration capacity: use of experimental design to evaluate the toxicity risk associated with remediation programs in long-lasting polluted areas
}

\section{Xavier Moreau}

Aix-Marseille-University: Aix-Marseille Universite

\section{Magalie Claeys-Bruno}

Aix-Marseille-University: Aix-Marseille Universite

Jean-Pascal Andraud

Aix-Marseille-University: Aix-Marseille Universite

Hervé Macarie

IRD: Institut de recherche pour le developpement

Daniel E Martínez

Pomona College

Maxime Robin

Aix-Marseille-University: Aix-Marseille Universite

Michelle Sergent

Aix-Marseille-University: Aix-Marseille Universite

Laetitia De Jong ( $\sim$ laetitia.dejong-moreau@imbe.fr)

Aix-Marseille-University: Aix-Marseille Universite https://orcid.org/0000-0001-8798-3131

\section{Research Article}

Keywords: bioassay, ecotoxicity, freshwaters, insecticide, organochlorine, modeling, experimental design

Posted Date: January 13th, 2022

DOI: https://doi.org/10.21203/rs.3.rs-1148896/v1

License: (c) (i) This work is licensed under a Creative Commons Attribution 4.0 International License.

Read Full License 


\section{Abstract}

Chlordecone (CLD), an obsolete insecticide, used in the French West Indies between 1972 and 1993, is persistent in the environment but can be dechlorinated either chemically or under the action of microorganisms. Therefore, if soil remediation programs based on these processes are implemented in areas still contaminated today, those will see their concentrations of dechlorinated derivatives increase and these compounds will be also found in freshwater by streaming, leaching and erosion processes. The purpose of the present study was to evaluate, at environmental concentrations, the toxic effects of mixtures of chlordecone and a three-chlorine substituted byproduct. A hydra clone, which has been confirmed to be Hydra vulgaris Pallas, 1766 has been retained for bioassays where the toxicity has been evaluated by regeneration capacity during exposure. Exposure to mixtures is complex to investigate by classical methods, therefore, an experimental design associated to a mathematical model has been used to predict the effects of all the mixtures and to detect the toxic influence of each compound. The predictive model is discussed regarding the stochastic "endocrine disruptor effect" of CLD. At probable environmental concentrations of the compounds in the mixture, results show that impairment of regeneration capacity is explained mostly by the presence of CLD in the mixtures and support the implementation of remediation programs aimed at dechlorination of this persistent organochlorine pesticide.

\section{Highlights}

Ecotoxicological assessment of environmental concentrations of chlordecone.

Evaluation of Hydra vulgaris regeneration capacity.

Low volume 96-well microplate bioassays with the cnidarian Hydra vulgaris.

Exposures to mixtures of chlordecone with a three-chlorine substituted byproduct.

Mathematical model to predict effects of the toxics in mixtures.

\section{Introduction}

Chlordecone $\left(\mathrm{C}_{10} \mathrm{Cl}_{10} \mathrm{O}, \mathrm{CLD}\right)$ is a persistent organochlorine insecticide which was formerly manufactured in the USA under the trade name of Kepone ${ }^{\circledR}$. One of the main uses of CLD has been for controlling black banana weevil populations. For this specific use, CLD was formulated as a very fine powder (also called dust by the pesticide industry) diluted to $5 \%$ by weight in a mineral matrix which was applied manually directly to the soil surface in circles around the banana pseudostem (Clostre et al. 2014a; Epstein 1978). Due to the mismanagement of the production process, most of the workers making CLD in the United States were poisoned by it, which resulted in the closure of the factory and the complete ban on production, commercialization and use of CLD in USA in 1977 (Cannon et al. 1978; Dawson et al. 1979). To cope with shortage of CLD due to this closure, a consortium of French banana producers succeeded to 
relaunch the production of CLD in 1982 under a new brand name, Curlone ${ }^{\circledR}$, with the objective of using it mostly in the banana plantations of French West Indies (FWI). Overall, either as Kepone ${ }^{\circledR}$ or Curlone ${ }^{\circledR}$, it is estimated that around 300 tons or $1 / 6$ of the CLD ever produced in the world have been used in FWI from 1972 to 1993 (Le Déaut and Procaccia 2009; Devault et al. 2016). Due to its physicochemical properties, especially a strong affinity for organic matter, CLD is highly persistent in soils. In the FWl, it has been estimated that depending on the soil composition, 60 to 700 years would be necessary before the almost complete CLD disappearance (Cabidoche et al. 2009). Although CLD exhibits weak water solubility (Dawson et al. 1979), under the action of rain, through leaching, runoff, and erosion, it is exported from the soil to surface and underground waters. From there, CLD reaches the coastline (Crabit et al. 2016; Mottes et al. 2020), contaminating the entire food chain (crops, farm animals as well as terrestrial, freshwater, and sea wildlife) including humans (Cabidoche and Lesueur-Jannoyer 2012; Coat et al. 2011; Dromard et al. 2019; Dyc et al. 2015; Jondreville et al. 2014; Lavison-Bompard et al. 2021; Méndez-Fernandez et al. 2018). The last study performed in 2013-2015 to evaluate the level of impregnation of the FWI population has shown that CLD was present in the blood of over $92 \%$ of the inhabitants of Guadeloupe and Martinique (Dereumeaux et al. 2020), who fear for their health since CLD is a suspected carcinogen for humans and a known neurotoxic compound and endocrine disruptor which may impact human reproduction (for a review of the health effects, see Multigner et al., 2016). To avoid the CLD contamination of the population by food, the authorities have taken several measures such as the installation of activated carbon filters in the water potabilization plants, the control of the type of cultures authorized in function of the soil contamination levels, ban on fishing in all rivers and in coastal areas, closure of most aquaculture farms and increased control of the carcass in slaughterhouses. This has impacted those living from these economic activities (farmers, breeders, fishermen, aquaculturists) and created a social crisis in FWI. To face this situation, soil remediation programs have been proposed since soil is the main source of contamination of all the other FWI ecological compartments. Some of these programs suggest adding CLD adsorbents to the soil (activated carbon, biochar, compost) to decrease or eliminate CLD transfers to water, crops, and breeding animals (Clostre et al. 2014b; Ranguin et al. 2020), to extract CLD from soil with plants (Liber et al. 2018) or to destroy CLD by microbial or physicochemical processes (Chevallier et al. 2019; Lomheim et al. 2020; Macarie et al. 2016; Mouvet et al. 2017). To date, among all these approaches, beside the addition of compost, the physicochemical In Situ Chemical Reduction (ISCR) process, which consists of adding $\mathrm{Fe}^{0}$ to the soil, is the only one to have been tested with some success under real environmental conditions in FWI, up to the plot scale (Mouvet et al. 2020). The ultimate fate of CLD during this process remains to be established but it is known that it will generate a series of dechlorination products which conserved the bishomocubane structure of CLD but have lost 1 to 7 chlorine atoms replaced by hydrogen atoms and known as hydrochlordecone. In absence of complete mineralization, there is always the risk that the degradation byproducts may have similar toxicity or be even more toxic than the parent compounds (Benoit et al. 2017; Dolfing et al. 2012). To address this question, the genotoxicity, mutagenicity and proangiogenic properties of 3 major CLD derivatives formed during the ISCR process, and which have lost 1, 3, and 4 chlorine atoms have been compared to that of CLD, showing that like CLD, they remained non-genotoxic and non-mutagens, while their proangiogenic properties tested both in vitro and in vivo were greatly reduced (Alibrahim et al. 2020; 
Legeay et al. 2017). To evaluate their respective toxicity potential, the three dechlorinated compounds were tested individually but during the ISCR process, they were present simultaneously in soil although in proportions that may fluctuate over time (e.g., Mouvet et al. 2020). In the same way, these byproducts will be transported to the other environmental compartments as a mixture in water (Ollivier et al. 2020a, b). Due to possible additive, synergistic or potentiation effects such mixtures containing CLD and CLD byproducts may have a greater toxic effect than CLD alone as observed for other compounds (e.g. Brown et al. 2014; Macaulay et al. 2021; Nørgaard and Cedergreen 2010; Yang et al. 2017).

In this context, the present study has been conducted to answer a fundamental question: are mixtures containing chlordecone and dechlorination byproducts, which may be formed during remediation processes, less or more toxic when the concentration of the dechlorinated product increases in the mixtures? To answer this question and in contrast with classical methods applied in ecotoxicology, where, for example, one concentration is modified at a time keeping the others constant in a mixture, we proposed an experimental design that allows: (i) to vary simultaneously all concentrations of the compounds of the mixture, (ii) to limit the number of experiments, (iii) to detect the influence of the compounds in the mixtures, (iv) to produce a predictive model of the toxicity of the mixtures and (v) to considerably reduce the amount of waste generated during the experimental procedure. The bioassays have consisted in evaluating the regeneration capacity of a freshwater hydra clone exposed, in 96 well polycarbonate microplates, to environmental concentrations of CLD in presence of corresponding concentrations of the trihydrochlordecone (CLD-3Cl) generated by the ISCR process. The CLD concentrations were in the range of those measured in FWI surface freshwaters (Lesueur-Jannoyer et al. 2016, Mottes et al. 2020). Hydra was chosen as a freshwater animal model for the study because it has been already used in a recent work to assess the effect of long-term exposure of CLD on several biological markers such as stress gene expression, oxidative stress endpoints and reproduction rate (Colpaert et al. 2020). The pertinence of this choice has been reinforced recently by the finding that Hydra species are ubiquitous in FWI surface waters (Macarie and Martínez, unpublished results). Preliminary to our investigation, the taxonomic position of the hydra clone used in the bioassays was definitively established.

\section{Material And Methods}

\section{Hydra clone culture conditions}

The population of the hydra clone (strain IMBE1) was raised in TES buffer ( $0.1 \mathrm{mM}$; pH 7) (Sigma-Aldrich, Saint Quentin-Fallavier, France), at $20^{\circ} \mathrm{C} \pm 0.1^{\circ} \mathrm{C}$ and under a $12 / 12 \mathrm{~h}$ light-dark cycle according to the procedure of De Jong et al. (2016) that has been adapted from Trottier et al. (1997). The polyps were fed every three to four days with $24 \mathrm{~h}$-hatched Artemia sp. nauplii ad libitum. All specimens used in this experiment raised from asexual reproduction and belong to the same clone.

\section{DNA Extraction, Sequencing and Phylogenetic analysis}


DNA from the IMBE1 hydra clone was extracted using the QIAGEN DNAeasy Blood \& Tissue Kit following manufacturer's protocol (final elution was $150 \mu \mathrm{l}$ ). Ribosomal DNA (the ITS region comprising $18 \mathrm{~S}$ partial; ITS1, 5.4 S complete, ITS2 and $28 \mathrm{~S}$ partial) was amplified by PCR $\left(94^{\circ} \mathrm{C}\right.$ for $3 \mathrm{~min}$; and 35 cycles of denaturing at $94^{\circ} \mathrm{C} 30 \mathrm{sec}$, annealing at $55^{\circ} \mathrm{C} 60 \mathrm{sec}$, extension at $72^{\circ} \mathrm{C}$ for $\left.90 \mathrm{sec}\right)$. The amplified fragment was verified by $1 \%$ agarose electrophoresis and cloned into a PROMEGA pGEM-T Easy vector (ligation was performed overnight at $4^{\circ} \mathrm{C}$ ). Sequencing was carried out by Eurofins Genomics.

The IMBE1 ITS sequence was first aligned with CLUSTAL Omega to hydra sequences from all 4 major clades of hydra: Viridissima, Braueri, Oligactis and Vulgaris (Martínez et al. 2010). Once the specific hydra group was determined, a second alignment was performed to investigate the geographic origin of the IMBE1 strain. This second alignment included a total of 76 hydra ITS sequences, 7 of which were used as outgroups in the phylogenetic analyses. A maximum likelihood analysis of the phylogenetic relationships was implemented using Garli 2.0 (Zwickl 2006). For this analysis, the invariant, and hence uninformative, $5.4 \mathrm{~S}$ portion of the sequence was not included in the alignment. The best likelihood model was selected based on the Akaike Information Criteria (AIC; Akaike 1987) using JModelTest (Guindon et al. 2010; Posada 2008). We used FigTree (version 1.3.1; Rambaut 2009) to plot the best phylogram produced by Garli. Maximum likelihood bootstrap values were calculated based on 1000 pseudo replicates using IQtree (Hoang et al. 2018; Nguyen et al. 2015) and Garli. Neighbor Joining bootstrap values were calculated based on 1000 pseudo replicates using PAUP (Swofford 2003).

\section{Toxicity evaluation}

In exposure experiments (see below in the "Experimental design" section), healthy and budding polyps of the hydra clone of similar size were randomly collected among a dense healthy population under a stereomicroscope. One day before the beginning of the experiment, the population was fed with living 24 h-hatched Artemia sp. nauplii. After two transverse cuts of the polyps retained for exposure, the central section of the hydra body, also called gastric region, was conserved for regeneration experiments (Figure 1).

Each section of the gastric region was carefully placed in a well of a 96 well-microplate either in $250 \mu \mathrm{L}$ of TES buffer $(0.1 \mathrm{mM}$; pH 7) for controls or in $250 \mu \mathrm{L}$ of a mixture solution of CLD and CLD-3Cl at concentrations defined according to an experimental design (see the following section). Then, the 96 wellmicroplates were placed into a thermo-regulated incubator at $20^{\circ} \mathrm{C} \pm 0.1^{\circ} \mathrm{C}$ under a $12 / 12 \mathrm{~h}$ light-dark cycle for $96 \mathrm{~h}$. Control conditions, performed in triplicate, were needed to ascertain the good health of the population of the hydra clone used in exposure experiments. In control conditions, the gastric region regenerates basal and oral regions following normal progressive steps according to time. The capacity of the hydra clone regeneration has been evaluated using a score scale ranging from 0 to 10 . The score scale used here has been built with different score scales proposed in previous studies (Pachura-Bouchet 2005; Park and Yeo 2012; Quinn et al. 2008; Vasseur and Pachura 2006; Wilby and Tesh 1990). The scale 
has been modified to consider not only stunted regeneration but also abnormalities and altered morphology in relation to toxicity (Table 1). 
Table 1

Regeneration capacity scores of gastric sections of IMBE1 hydra clone specimens after $96 \mathrm{~h}$ of exposure.

Shape of polyp at the end of the exposure time

"Reference scores"

Normal progressive steps of regeneration

length $>1.1 \mathrm{~mm}$
Mouth, four to height long tentacles

(length $>1 / 2$ of body length), body

Mouth, four to height long tentacles

9

(length $>1 / 2$ of body length), body

length $<1.1 \mathrm{~mm}$

Mouth, two to three long tentacles

(length $>1 / 2$ of body length), body

Mouth, two to three long tentacles

(length $>1 / 2$ of body length), body

length $<1.1 \mathrm{~mm}$

Mouth, one long tentacle (length $>1 / 2 \quad 7.5$

of body length), body length $>1.1$

$\mathrm{mm}$

Mouth, one long tentacle (length $>1 \frac{1}{2} \quad 7$

of body length), body length $<1.1$

$\mathrm{mm}$

Mouth, short tentacles, hydra body

length $>1.1 \mathrm{~mm}$

Mouth, short tentacles

Basal disk and short tentacles

Basal disk and beginning of tentacle

Basal disk only or beginning of tentacle only

Normal wound healing

no basal regeneration or normal

tentacles but at wrong location

Number of long normal tentacles >

number of abnormal tentacles

(bulbed or split into two...)

Number of long normal tentacles $=$ number of abnormal tentacles

(bulbed or split into two...)

10

8.5

8

7

.

6.5

6

5

4

3

2 length $>1.1 \mathrm{~mm}$

Regeneration score

Toxicity signs: malformations, and loss of physiological functions 


\begin{tabular}{|ll|}
\hline \multicolumn{1}{|l}{$\begin{array}{l}\text { Shape of polyp at the end of the } \\
\text { exposure time }\end{array}$} & $\begin{array}{c}\text { Regeneration } \\
\text { score }\end{array}$ \\
\hline $\begin{array}{l}\text { Number of long normal tentacles }< \\
\text { number of abnormal tentacles } \\
\text { (bulbed or split into two...) }\end{array}$ & $\begin{array}{l}\text { reference } \\
\text { score }-3\end{array}$ \\
\hline $\begin{array}{l}\text { No mouth, basal disk, long tentacles } \\
\text { (length }>1 / 2 \text { of body length) and/or } \\
\text { body }>1.1 \text { mm }\end{array}$ & 5 \\
\hline $\begin{array}{l}\text { Loss of osmoregulation (bleaching, } \\
\text { abnormal conic shape...), mouth }\end{array}$ & 5 \\
\hline $\begin{array}{l}\text { Loss of osmoregulation (bleaching, } \\
\text { abnormal conic shape...), no mouth }\end{array}$ & 4 \\
\hline $\begin{array}{l}\text { No wound healing } \\
\text { Disintegrated }\end{array}$ & 1 \\
\hline $\begin{array}{l}0 \text { to } 1=\text { death; } 2 \text { to } 5.9=\text { extremely toxic; } 6 \text { to } 6.9=\text { very toxic; } 7 \text { to } 7.9=\text { toxic; } 8 \text { to } 8.9=\text { low toxicity, } \\
\text { viable polyp; } 9 \text { to } 10=\text { no toxicity, healthy polyp. }\end{array}$ \\
\hline
\end{tabular}

\section{Experimental design}

Two quantitative factors $\left(\mathrm{U}_{1}, \mathrm{U}_{2}\right)$ were studied: CLD and CLD-3Cl concentrations and the aim of this study was to model the effects of mixtures of CLD and CLD-3Cl. In other words, the idea was to obtain the value of hydra regeneration score over the whole domain of interest in the range of CLD environmental concentrations observed in the rivers of French West Indies Islands. The results of various sampling campaigns have found for instance that over $50 \%$ of the rivers of Martinique contain CLD concentrations ranging from values just above the analytical limit of quantification, e.g. $0.003 \mu \mathrm{g} \cdot \mathrm{L}^{-1}$ up to $20 \mu \mathrm{g} \cdot \mathrm{L}^{-1}$ and that the yearly average CLD concentration of all these rivers varies between 0.6 to $0.86 \mu \mathrm{g} \cdot \mathrm{L}^{-1}$ depending on the years (Arqué and Bocaly 2020; Cattan et al. 2019; Mottes et al. 2017). Hence, the limits of experimental range selected according to lower and higher CLD environmental concentrations, i.e. 0.1 $\mu \mathrm{g} . \mathrm{L}^{-1}$, corresponding to $2.10^{-4} \mu \mathrm{M}$ (or $0.000204 \mathrm{mM}$ ), and $20 \mu \mathrm{g} \cdot \mathrm{L}^{-1}$, corresponding to $4.10^{-4} \mu \mathrm{M}$ (or $0.040738 \mathrm{mM}$ ), are defined in Table 2. The same ranges of molar concentrations have been used for CLD3Cl (Table 2). 
Table 2

Experimental domain of interest between the two studied quantitative factors which are: concentration of CLD $\left(\mathrm{U}_{1}\right)$ and of CLD-

$3 \mathrm{Cl}\left(\mathrm{U}_{2}\right)$.

\begin{tabular}{|lll|}
\hline \multicolumn{3}{|l|}{ Limits of experimental domain } \\
\hline Coded values & $\mathrm{X}_{1}$ & $\mathrm{X}_{2}$ \\
\hline Quantitative factors & \multicolumn{1}{l|}{ Real values } \\
\hline $\mathrm{U}_{1}([\mathrm{CLD}]$ in $\mu \mathrm{M})$ & $2.10^{-4}$ & $4.10^{-2}$ \\
\hline $\mathrm{U}_{2}([\mathrm{CLD}-3 \mathrm{Cl}]$ in $\mu \mathrm{M})$ & $2.10^{-4}$ & $4.10^{-2}$ \\
\hline
\end{tabular}

Within the defined experimental domain, the possibility of different mixtures represents an infinite number of experiments. Therefore, to determine the effects of all mixtures, we have chosen a mathematic tool allowing to collect the maximum of information using a minimum of experiments. This tool is an empirical model which can represent the hydra regeneration score (noted $\mathrm{Y}$ in the equation below) in the domain of interest i.e. for all combinations of CLD and CLD-3Cl concentrations. We have postulated a quadratic polynomial model since it allows the consideration of curvature effects and to understand the influence of each quantitative factor $(\mathrm{U}$, Table 2$)$. This model based on two predictor variables, CLD and CLD-3Cl concentrations, with coded variables $\mathrm{X}_{1}$ and $\mathrm{X}_{2}$ was written as follows:

$Y=b_{0}+b_{1} X_{1}+b_{2} X_{2}+b_{11} X_{1}^{2}+b_{22} X_{2}^{2}+b_{12} X_{1} X_{2}$

To estimate the coefficients of the mathematical model, experiments were carefully chosen by the experimental design. Indeed, the quality of the coefficient estimation and the quality of the prevision only depended on the choice of the experimental points and were independent of experimental results (Box and Hunter 1954; 1957; Droesbeke et al. 1997; Sarabia and Ortiz 2009). Among the set of optimal designs for a quadratic model, we have chosen a centered composite design with nine points (rectangles in figure 2). To validate the model, we have added four "validation points" inside the domain (ovals in figure 2). The last step of the experimental strategy allows considering the possible stochastic "endocrine disruptor effect". For that purpose, we have added six points (stars in figure 2): three mixtures containing $2.8810^{-3}$ $\mu \mathrm{M}$ of CLD (i.e. $1.4 \mu \mathrm{g} . \mathrm{L}^{-1}$ of CLD) and variable increasing CLD-3Cl concentrations (experiments 16,17 and 18); three mixtures containing $2.8810^{-3} \mu \mathrm{M}$ of CLD-3Cl and variable increasing CLD concentrations (experiments 14,15 and 18). The choice of the $2.8810^{-3} \mu \mathrm{M}$ concentration of CLD was supported by the study of Colpaert et al. (2020), that have demonstrated stochastic "endocrine disruptor effect" at a concentration of $1 \mu \mathrm{g} \cdot \mathrm{L}^{-1}$ of CLD for several biological endpoints after 14-day exposure of entire polyps of the same Hydra species. 
Table 3

Experimental design with 18 different experimental conditions and their respective hydra regeneration score determined after $96 \mathrm{~h}$ exposure to chlordecone (CLD) and trihydrochlordecone (CLD-3Cl) mixture.

\begin{tabular}{|c|c|c|c|c|c|c|}
\hline \multirow[t]{3}{*}{$\begin{array}{l}\text { Experimental } \\
\text { conditions }\end{array}$} & \multicolumn{2}{|c|}{$\begin{array}{l}\text { Coded } \\
\text { values }\end{array}$} & \multicolumn{2}{|c|}{ Real values } & \multirow[t]{3}{*}{$\begin{array}{l}\text { Number } \\
\text { of } \\
\text { replicates }\end{array}$} & \multirow[t]{3}{*}{$\begin{array}{l}\text { Mean regeneration score } \pm \\
\text { Standard Error Mean (SEM) }\end{array}$} \\
\hline & $\mathrm{X} 1$ & $\mathrm{X} 2$ & U1 & U2 & & \\
\hline & & & $\begin{array}{l}\text { [CLD] in } \\
\mu \mathrm{M}\end{array}$ & $\begin{array}{l}{[\mathrm{CLD}-3 \mathrm{Cl}]} \\
\text { in } \mu \mathrm{M}\end{array}$ & & \\
\hline 1 & -1 & -1 & $2.10^{-4}$ & $2.10^{-4}$ & 3 & $7.5 \pm 1.0$ \\
\hline 2 & +1 & -1 & $4.10^{-2}$ & $2.10^{-4}$ & 6 & $6.8 \pm 1.5$ \\
\hline 3 & -1 & +1 & $2.10^{-4}$ & $4.10^{-2}$ & 6 & $9.2 \pm 0.4$ \\
\hline 4 & +1 & +1 & $4.10^{-2}$ & $4.10^{-2}$ & 3 & $5.0 \pm 0.9$ \\
\hline 5 & -1 & 0 & $2.10^{-4}$ & $2.04 .10^{-2}$ & 3 & $8.3 \pm 0.8$ \\
\hline 6 & +1 & 0 & $4.10^{-2}$ & $2.04 .10^{-2}$ & 3 & $7.8 \pm 1.6$ \\
\hline 7 & 0 & -1 & $2.04 .10^{-2}$ & $2.10^{-4}$ & 3 & $8.7 \pm 0.3$ \\
\hline 8 & 0 & +1 & $2.04 .10^{-2}$ & $4.10^{-2}$ & 3 & $8.5 \pm 0.5$ \\
\hline 9 & 0 & 0 & $2.04 .10^{-2}$ & $2.04 .10^{-2}$ & 3 & $7.3 \pm 1.1$ \\
\hline 10 & -0.5 & -0.5 & $1.02 .10^{-2}$ & $1.02 .10^{-2}$ & 3 & $8.3 \pm 0.8$ \\
\hline 11 & -0.5 & 0.5 & $1.02 .10^{-2}$ & $3.6 .10^{-2}$ & 3 & $9.5 \pm 0.7$ \\
\hline 12 & 0.5 & -0.5 & $3.6 .10^{-2}$ & $1.02 .10^{-2}$ & 3 & $7.7 \pm 1.0$ \\
\hline 13 & 0.5 & 0.5 & $3.6 .10^{-2}$ & $3.6 .10^{-2}$ & 6 & $5.5 \pm 2.0$ \\
\hline 14 & -1 & -0.87 & $2.10^{-4}$ & $2.88 .10^{-3}$ & 3 & $9.2 \pm 0.8$ \\
\hline 15 & +1 & -0.87 & $4.10^{-2}$ & $2.88 .10^{-3}$ & 3 & $8.7 \pm 0.3$ \\
\hline 16 & -0.87 & -1 & $2.88 .10^{-3}$ & $2.10^{-4}$ & 6 & $4.2 \pm 0.8$ \\
\hline 17 & -0.87 & +1 & $2.88 .10^{-3}$ & $4.10^{-2}$ & 6 & $5.0 \pm 0.6$ \\
\hline 18 & -0.87 & -0.87 & $2.88 .10^{-3}$ & $2.88 .10^{-3}$ & 6 & $4.8 \pm 0.7$ \\
\hline
\end{tabular}

Eighteen different experimental conditions were performed, and each experimental condition has been at least repeated in triplicate (Figure 2). Finally, a total of 72 experiments have been carried out (Table 3). 


\section{Chemicals and reagents}

CLD in the form of a powder with a purity over $97 \%$ was a gift from Azur Isotope (Marseille, France). CLD-

$3 \mathrm{Cl}$ was synthesized by Alpha Chimica (Châtenay-Malabry, France) and was also provided as a powder. It had a chromatographic purity over $90 \%$ expressed as $\%$ of the total area of peaks detected (Figure $3 \mathrm{~A}$ ). The position of the substitution of the chlorine atoms by hydrogen atoms on the CLD-3Cl carbon chain was unknown with precision. The predominant mode of fragmentation on electronic impact of the compounds with a bishomocubane structure such as CLD-3Cl is known to correspond to the cleavage in half, of their cage forming two pentacyclo-fragments (Dilling and Dilling 1967). According to this rule, the main fragments detected (m/z 202, 181 and 167) by GC-El-MS (Gas Chromatography - Electronic impact - Mass spectrometry) for the Alpha Chimica product, suggested that among the 36 possible isomers of CLD-3Cl (Dolfing et al., 2012), it could correspond to one of the 15 isomers drawn on figure 3B. A further analysis by Nuclear Magnetic Resonance showed that the Alpha Chimica product was in fact a mixture of two CLD-3Cl isomers in a ratio of 3:1 which coeluted and could not be resolved during GC analysis (Pierre-Loïc Saaidi, Genoscope, France, personal communication). The CLD-3Cl of Alpha Chimica gave the same retention time and mass spectra than the CLD-3Cl generated by the ISCR process upon GC-EIMS analysis (Sébastien Bristeau, BRGM, France, personal communication).

Stock solutions of CLD and CLD-3Cl were prepared by dissolving $1 \mathrm{mg} \mathrm{CLD.L^{-1 }}(2.04 \mu \mathrm{M})$ in pure water and $1.74 \mathrm{mg} \mathrm{CLD}-3 \mathrm{Cl}^{-L^{-1}}(4.08 \mu \mathrm{M})$ in $0.1 \mathrm{M}$ TES buffer (Sigma-Aldrich, Saint Quentin-Fallavier, France). In exposure experiments, the stock solutions of CLD and CLD-3Cl were freshly diluted in the hydra breeding media, i.e. $0.1 \mathrm{mM}$ TES buffer at wanted concentrations of the mixtures see "Experimental design" section.

\section{Results}

\section{Phylogenetic affinities and geographical origin of the IMBE1 strain}

The observation of the IMBE1 clone nematocysts under the microscope suggested that the strain could belong to the Vulgaris clade. However, the morphological characterization of hydra is not always reliable and does not permit to establish the geographic origin of a particular strain. An initial alignment of the IMBE1 ITS region to sequences of hydra from each of the four known clades (Viridissima, Braurei, Oligactis, and Vulgaris, Martínez et al. 2010) unequivocally placed the IMBE1 strain within the Vulgaris group. Fortunately, hydra within this clade show distinct ITS sequence patterns depending on their geographical distribution. We generated a second alignment which included $67 \mathrm{H}$. vulgaris sequences from all continents inhabited by the species. Sequences of 7 strains of the Oligactis clade (sister clade to Vulgaris) belonging to the three known species in that group were also included as outgroups. Using the Akaike Information Criteria (Akaike 1987) implemented by JModelTest (Posada 2008; Guindon et al. 2010), we determined that the best substitution model for this data set was HKY+G (Hasegawa et al. 
1985). The variation in substitution rates between different sites was Gamma distributed. The maximum likelihood phylogram generated implemented using Garli 2.0 (Zwickl 2006) clearly showed that strain IMBE1 is a Eurasian hydra most likely from Europe (Figure 4). The bootstrap values calculated by three different methods indicate the topology of the tree is quite robust which adds a high degree of certainty to our conclusion.

\section{Regeneration scores and toxicity scale}

In control conditions, values of regeneration scores recorded after 96 hours were of 10 suggesting that the polyp population was healthy at the beginning of exposures. In exposure conditions, among the malformations and damages observed, stunted regeneration, lack of mouth, abnormal tentacles (bulbed, short...) and loss of physiological functions (i.e., osmoregulation) are concerning because they impair nutrition (catching and ingestion of living preys) and lead to polyp death. Therefore, using the mean regeneration scores, the following toxicity scale can be proposed: score 0 to $1=$ death; score 2 to $5.9=$ extremely toxic; score 6 to 6.9 = very toxic; score 7 to $7.9=$ toxic; score 8 to $8.9=$ low toxicity, viable polyp; score 9 to $10=$ no toxicity, healthy polyp. Only mean regeneration scores below 8 are concerning (Table 1). The experimental results into the domain of interest are summarized in figure 5.

In the conditions of the experimental design, no mixture led to the death of the polyp after $96 \mathrm{~h}$ of exposure. At the minimal CLD concentration $\left(2.10^{-4} \mu \mathrm{M}\right)$ (Figure 2, experiments $\left.1,3,5\right)$, disturbing conditions were only observed in the mixture containing the lowest CLD-3Cl concentration i.e. $2.10^{-4} \mu \mathrm{M}$ (mean regeneration score $7.5 \pm 1.4$ ) and when CLD-3Cl concentrations increased in the mixture, hydra regeneration scores increased, reflecting low toxicity or no toxicity (mean scores of $8.3 \pm 0.8$ and $9.2 \pm$ 0.8 , respectively) (Figure 5). Regeneration scores were very low for all mixtures containing $2.88 .10^{-3} \mu \mathrm{M}$ of CLD (Figure 2, experiments 16, 17 and 18) whatever the concentrations of CLD-3Cl in the mixtures: mean scores varied between $4.2 \pm 0.8$ and $5.0 \pm 0.6$, indicating extremely toxic effects and thus very disturbing exposure conditions (Figure 5). Therefore, these observed impacts on regeneration capacity could be attributed to CLD alone.

At CLD concentrations of $10^{-2} \mu \mathrm{M}$ (experiments 10 and 11), mean regeneration scores were above 8 and did not evidence any greater toxic effects of the mixture (mean regeneration scores $8.3 \pm 0.8$ and $9.5 \pm$ $0.7)$.

In the middle of exposure domain for CLD concentration $\left(X 1=0 ; 2.04 .10^{-2} \mu \mathrm{M}\right)$, toxicity was only observed in the mixture containing 2.04.10-2 $\mu \mathrm{M}$ of CLD-3CI ( $\mathrm{X} 2=0$; mean regeneration score $7.3 \pm 1.1$, experiment 9 ) while for lower or higher CLD-3Cl concentrations, only a low toxicity was observed (mean regeneration scores 8.7. \pm 0.3 and $8.5 \pm 0.5$, respectively in experiments 7 and 8 ).

In all mixtures with CLD concentrations above $2.04 .10^{-2} \mu \mathrm{M}$ (right part of the experimental domain in Figure 5), regeneration scores reaching 8.9 or more were not observed. One mixture has shown a low 
toxicity and all other ones led to disturbing conditions. Two of them were extremely toxic (mean regeneration scores $5.5 \pm 2 ; 5.0 \pm 0.9$, experiments 13 and 4) and revealed that these severe toxic effects could be attributed to both compounds at high concentrations.

For the modeling step, we considered the nine points of the composite design (rectangles in figure 2) to calculate the model coefficients using multilinear regression on the coded variables $\left(X_{1}\right.$ and $\left.X_{2}\right)$. This model was then validated using the four "validation points" (ovals in figure 2 ) which experimental values have been further compared to the previously calculated ones. Data showed a non-significative difference (Student Test) with significance values largely above $5 \%$ indicating that the model and the experimental values were close. These four "validation points" were thus integrated for the calculation of the coefficients. The model can be written as follows:

$Y($ Score $)=7.99-0.97 X_{1}-0.09 X_{2}-0.51 X_{1}^{2}-0.10 X_{2}^{2}-0.96 X_{1} X_{2}$

This mathematical model was used to predict, whatever the proportions of CLD and CLD-3Cl in the mixtures, all the regeneration scores $(Y)$ inside the experimental domain (Figure 5). However, the mathematical model was not able to predict the stochastic "endocrine disruptor effect" observed at CLD concentration of $2.88 .10^{-3} \mu \mathrm{M}$ (experiments 16,17 and 18; at these experimental conditions low regeneration scores reflecting extremely toxic conditions were observed). Therefore, the 6 points of the matrix that have been added to the experimental design to study the possible stochastic "endocrine disruptor" effect were not used in the calculation of the model (experiments 14, 15 16, 17 and 18; stars in figure 2).

The modeling shows isoscore lines, i.e. different mixtures of CLD and CLD-3Cl leading to the same score of regeneration of $\mathrm{H}$. vulgaris (Figure 6). The generally vertical direction of the isoscore lines points out the preponderant effect of CLD in the mixtures. The presence of CLD-3Cl in the mixtures has no particular influence on the regeneration scores i.e. on the toxicity. Furthermore, for the minimal CLD concentrations tested, higher CLD-3Cl concentrations in the mixtures led to better regeneration scores, isoscores 8.5 and 9 , reflecting low or no toxicity, respectively. At the highest concentrations of both compounds, the model predicts very disturbing regeneration scores reflecting very toxic conditions. These very toxic conditions were explained by the presence of both compounds in the mixtures.

\section{Discussion}

In present study, the classification of our hydra IMBE1 clone has been reevaluated to dispel doubt concerning its species name. At the time of writing, this clone has been in breeding for at least the past four decades. In the early 1980's, it was used at the University of Philadelphia (USA) under the name Hydra attenuata in a prescreening test for the detection of substances with teratogenic potential in mammals (e.g. Johnson et al. 1982). The same clone was later used also by Environment Canada, and in France, in the Universities of Lorraine and Aix Marseille in standardized assays to assess the toxicity of polluted freshwaters and wastewaters as well as pure chemical compounds (Blaise and Kusui 1997; 
Blaise et al. 2018; Colpaert et al. 2020; De Jong et al. 2016; Pachura et al. 2005; Pachura-Bouchet et al. 2006; Quinn et al. 2008). Due to the confusion created by Schulze in 1917 around the name " attenuata » which has been used both to describe specimens belonging to the Hydra vulgaris and Hydra circumcincta species (Campbell 1989), the clones used in the previously cited works were either named as Hydra attenuata or Hydra circumcincta. The phylogenetic tree generated for this study clearly showed that the closest relatives of our IMBE1 clone, which had travelled between North America and Europe, belonged to the Hydra vulgaris species and were of European origin suggesting that it had itself the same geographic origin.

The outstanding regeneration capacity of species of Hydra genus has been successfully used in ecotoxicology by several authors to detect the teratogenic potential of numerous chemicals. To our knowledge, the pioneer was Johnson (1980) who used pellets of hydra dissociated cells as 'artificial embryo'. Interestingly, using eight pharmaceuticals already evaluated in mammals (dexamethasone, aspirin, retinol acetate, methotrexate, actinomycin $D$, vinblastine and non-acetylated isoniazid), he demonstrated that the low expensive hydra assays both performed on entire adult polyps and on 'artificial embryos' could be useful to identify non-coaffective and coaffective teratogens as adequately than the expensive mammalian assays on rodents. In subsequent studies (Johnson et al. 1982; Johnson and Gabel 1983), Johnson and collaborators further expanded their original findings to a greater family of compounds including formaldehyde, benzene, lithium carbonate, lithium chloride, DMSO, flavor enhancers, food additives (e.g. monosodium glutamate), phenylenediamine (hair dye product), saccharine, colchicine as well as several phthalates (dimethyl phthalate, diethyl phthalate, dibutyl phthalate) which are known endocrine disruptors (EDs) (e.g. Mathieu-Denoncourt, 2015 for review). For all these compounds, Johnson and collaborators found a good correlation between the A/D ratios observed for hydra and mammals where $A$ represents the toxic concentration for adults whereas $D$ represents the toxic concentration affecting development. The hydra assay was sensitive enough to identify among these compounds those capable to pose hazards to development and could be used as predictive of a putative teratogen's hazard potential (A/D ratio) before performing standard mammal assays (Johnson and Gabel 1983). Later, 'gastric sections' have been used as 'artificial embryo' by Wilby and Tesh (1990). As the assay based on 'gastric sections' was easier to perform than the one using pellets of dissociated cells, it has been reused by several authors (e.g. Pachura-Bouchet 2005; Park and Yeo 2012; Quinn et al. 2008; Vasseur and Pachura 2006). The sensitivity of this 'hydra artificial embryo' assay has been previously demonstrated. For example, in the case of nonylphenol exposure, a family of ED compounds found in wastewaters (e.g. Filali-Meknassi et al. 2004), hydra regeneration was disrupted at concentrations three times lower than those leading to adult lethality (Pachura-Bouchet et al. 2006). The present study confirms the sensitivity of this bioassay, and therefore reaffirmed the need of such investigations for risk assessment with environmental concentrations of xenobiotics. The simple diploblastic organization of these animals only consists in two differentiated tissues. Therefore, cnidarians lack complex endocrine system that can be found in vertebrates and several invertebrates (e.g. Arthropoda). Even if physiological regulation and potential disruption are poorly understood in cnidarians, common vertebrate hormones (e.g., steroids, iodinated organic compounds, neuropeptides, and 
indolamines) have been identified in their tissues and chemical stressors could also impact the physiology of these invertebrates (Tarrant 2005). Keeping in mind that, in contrast to most metazoans, cnidarian cells are not generally organized into organs or systems, with careful consideration, the hydra regeneration assay can be a useful predictor of the potential risk to a developing vertebrate embryo (Bowden et al. 1995). But of course, as pointed out by Tarrant (2005), "care must be taken not to assume processes will be identical in all organisms". In other words, teratogenic effects on "hydra artificial embryo' exposed to toxicants could reflect teratogenic effect of mammal embryos but no conclusions could be formulated concerning the involved physiological mechanisms. In the present study, in which we have used 'gastric sections' as 'artificial embryo', teratogenic effects could be observed in several mixtures. The presence of CLD-3Cl had no particular influence on the toxicity of the mixtures, except when both CLD and CLD-3Cl were at their highest levels. For these latter conditions, both compounds could explain the high toxicity of the mixture. Such conditions are however unlikely to occur in the environment as the result of a soil remediation process such as the ISCR one. In first approach, the dechlorination of CLD to generate CLD-3Cl will result in a decrease of CLD concentration in the soil while that of the dechlorination product will increase and so a high concentration of both compounds cannot be present at the same time. In any case, since it will be only possible to apply the remediation processes over a few tens of centimeters of the upper part of the soil, the CLD stock in the lower parts will remain intact. Under such conditions, the work of Ollivier et al $(2019,2020)$ with column of soils treated in surface by ISCR has clearly shown that the concentrations of CLD-3Cl, but also those of the other dechlorination products will always be lower than CLD in the soil leachates that contaminate the surface and ground waters even if these products are more soluble and so mobile than CLD. Since the ban of CLD field utilization, CLD concentrations in freshwaters could increase solely if CLD stored in soil matrix is released. In a recent study conducted in FWI, Sabatier and colleagues (Sabatier et al. 2021) demonstrate CLD resurgence due to the widespread use of herbicides containing glyphosate since the late $1990 \mathrm{~s}^{\prime}$. This still current agricultural practice is considered to be responsible of a hitherto unseen rise in soil erosion and downstream of a major release of the stable CLD stored in polluted soils since their ban (Sabatier et al. 2021). The severe toxic effects observed at high CLD and CLD-3Cl concentrations on hydra development supports a special warning of agricultural practices that could remobilize CLD and lead to increasing CLD concentrations in freshwaters. In present study, teratogenic effects on 'hydra artificial embryo' exposed to the most environmental probable mixtures can be explained by the presence of CLD in the mixture. Indeed, for a given CLD concentration, regeneration scores did not differ when CLD-3Cl concentration increased while scores fluctuate between bad to good when CLD concentrations vary for a given CLD-3Cl concentration. Thus, it seems that the presence of CLD-3Cl in the mixtures, at concentrations expected after the application of a remediation process such as the ISCR, has no supplementary deleterious effect on hydra regeneration capacity. Regeneration scores reflecting no sign of toxicity (score up to 9) can only be observed in the mixtures with CLD concentrations equal or below to 1.02.10 ${ }^{-2} \mu \mathrm{M}\left(5 \mu \mathrm{g} \cdot \mathrm{L}^{-1}\right)$ (experiments 3,11 and 14 in figure 2). However, the CLD concentration at 2.88.10 ${ }^{-3} \mu \mathrm{M}\left(1.4 \mu \mathrm{g} . \mathrm{L}^{-1}\right)$ (experiments $16,17,18$ in figure 2 ) appears as a critical concentration leading to decrease of regeneration scores reflecting greater toxic conditions. Interestingly, a CLD concentration which is only 3.5 times higher in the mixture $\left(1.02 .10^{-2} \mu \mathrm{M}\right.$, i.e. $5 \mu \mathrm{g} \cdot \mathrm{L}^{-1}$, experiments 10 and 11 in figure 
2) has led to a return to satisfactory regeneration. Hence, our experimental results demonstrate that the toxic effects could not be linked to a progressive gradient of CLD concentration in the mixtures as impairments of regeneration have been observed at both low and high critical concentrations of CLD. The present results clearly demonstrated that the nonmonotonic concentration-response occurred with these organochlorine mixtures because (1) low or high concentrations could lead to the same deleterious damages and (2) because exposition to low and close to low concentrations could lead to good or bad regeneration capacities. Thus, whereas the teratogenic effect could be explained by the presence of CLD in the mixtures, it was not dependent on an increase in CLD concentrations. Such stochastic phenomenon has been also recently described concerning several biological endpoints in hydra entire polyps under exposure to CLD: reproductive rates, morphological changes, and expression of target stress genes (Colpaert et al. 2020). Therefore, our results confirm the previous observations of Colpaert et al. (2020) and lead to the same conclusion: biological effects observed after exposure to CLD follow nonmonotonic dose-response curves. The nonmonotonic dose-response effects are difficult to model, and this phenomenon is a challenge in ecotoxicology because, in absence of a suitable mathematical model to estimate the risk, the presence of such compounds in the environment, whatever their concentrations, represent a threat for exposed populations. Our study pointed out the difficulty to propose a predictive mathematical model when studying compounds belonging to EDs. Without considering the unpredictable stochastic effects of EDs, our experimental design allows to propose an empirical model that can determine the hydra regeneration score (noted $Y$ in the equation of the model) in the domain of interest i.e. for all combinations of concentrations (Figure 6). The approach can also provide information on the most active compounds in the mixtures. From the present data, it can be suggested that our approach is useful to study the mixtures containing compounds having concentration-dependent effects. With a reduced number of experiments, it is possible to model the value of the quantifiable biological responses and to obtain a predictive effect for any combination in the concentration domain. Our method offers an alternative to the isobologram method (Sørensen et al. 2007) as both methods share common advantages such as their simplicity and flexibility (Greco et al. 1995). In a review of studies conducted from 2007 to 2017 either in ecotoxicology or mammalian toxicology (human included), Martin et al. (2021) stated that the isobologram method represents about $12 \%$ of mixture investigations. In contrast to our method, the isobologram method needs to determine the biological response beforehand for each compound of the mixture and therefore need more experiments. As our method, the isobologram method could not predict stochastic EDs effects. The isobologram method directly applies the definition of addition of concentrations. Isoboles connect different combinations of doses that produce the same effect and since 2000s', the effect of the three types of interactions of compounds in mixtures (additivity, antagonism, and synergism) has been determined with the model of Concentration Addition (CA) for substances sharing the same mechanism of action, and under the independent model Action (IA) for those with a different mechanism of action. In our method, there is no need to know the effect of single compound: only the effects of the compounds in mixtures are investigated. Therefore, both methods offer advantages and disadvantages, and the choice of the method depends on the objective of the study. If the objective is to investigate mechanisms of action and determine additive, antagonist or synergistic effects so the isobologram method must be retained. On the other hand, if the objective is to

Page 16/28 
predict the effects of all combinations of mixtures in a range of defined concentrations using a minimum number of experiments, our method is a better choice. The two methods using various mixture ratios are preferable to classical design mixtures. Nevertheless, methods using various mixture ratios represent only $5 \%$ of experimental designs (Martin et al. 2021). According to Martin et al. (2021), classical designs with mixtures of two compounds generally consist of a simple combination of concentrations in mixtures. For example: (1) the two chemicals are tested alone at low, medium, and high concentrations, then in mixture, at the same concentrations (e.g. low concentrations together, medium concentrations together and high concentrations together); (2) the concentration of one compound is fixed while the concentrations of the other vary but in a limited number of conditions. A breakthrough in mixture investigations was the possibility to construct response surfaces and this possibility is also offered with our experimental design as well as the isobologram method. However, response surfaces of the biological effects are still underrepresented in literature as they represent only 5\% of studies from 2007 to 2017 (Martin et al. 2021).

Biological effects of environmental mixtures are puzzling in the cases of EDs and the investigations about EDs challenge the Paracelsus principle "the dose makes the poison". The European Union regulation states three categories to achieve a good water quality: (1) A river is considered to be in a "good chemical status" if pesticide concentration is not more than $0.1 \mu \mathrm{g} \cdot \mathrm{L}^{-1} ;(2)$ a river is considered to be in a "poor chemical status" when the sum of pesticide concentrations exceeds $0.5 \mu \mathrm{g} . \mathrm{L}^{-1}$; and (3) a river is considered untreatable for water consumption if pesticide concentration exceeds $2 \mu \mathrm{g} . \mathrm{L}^{-1}$. According to this guideline and when considering only CLD concentrations, all latter categories are encountered in the FWI freshwaters. However, our results indicate that even at low CLD concentrations in the mixtures $\left(0.1 \mu \mathrm{g} . \mathrm{L}^{-1}\right)$, regeneration capacity of $H$. vulgaris could be impaired. Previous authors have pointed out that EDs could have higher or similar effects at low concentrations than at higher concentrations (Gore et al. 2015; Vandenberg et al. 2012). In accordance with previous studies using adult hydra polyps (Colpaert et al. 2020), our results show the need to investigate biological effects after exposure to low CLD concentrations. Using the same hydra clone as in present work, Colpaert et al. (2020) have shown asexual reproduction impairments, morphological damages, and modulations of the expression of target genes involved in oxidative stress, detoxification, and neurobiological processes after exposure to low concentrations of $\operatorname{CLD}\left(0.1 \mu \mathrm{g} \cdot \mathrm{L}^{-1}\right)$. In the same way, using the giant freshwater prawn Macrobrachium rosenbergii, a crustacean living in FWI, Gaume et al. (2015) have also pointed out the necessity to investigate biological effects of low environmental concentrations of CLD. Indeed, after exposure to low CLD $\left(0.115\right.$ and $\left.0.2 \mu \mathrm{g} \cdot \mathrm{L}^{-1}\right)$ concentrations, these authors have demonstrated an induction of genes involved in biotransformation processes and in defense mechanisms against oxidative stress in M. rosenbergii (Gaume et al. 2015). Thus, in agreement with previous studies, our results confirm the need for a better knowledge of the stochastic effects of EDs.

\section{Conclusion}

Our work confirms that hydra regeneration assay is a useful, inexpensive and rapid screen for the evaluation of mixture toxicity. The use of empirical mathematical model offers perspectives in

Page $17 / 28$ 
environmental toxicology investigations, as this tool allows to study complex mixtures (with more than two products). Moreover, the quantitative factors (U1, U2, U3, ...) could either be only compound concentrations, or compound concentrations and abiotic factors such as temperature or exposure time. For example, using a similar experimental design, De Jong et al. (1994) have studied the toxicity of methyl mercury and mercury (II) chloride to a brown alga in mixtures containing calcium according to exposure time. In the present study, the values calculated by the model are close to the experimental values and therefore increase confidence in such predictive approach for a better knowledge of mixtures effects. Toxic effects of organochlorine pesticides and byproducts are difficult to analyze with classical ecotoxicity tools and the present experimental design offers possibility to detect the stochastic effects of such compounds even if no adequate modelling could be proposed to predict them. Our experimental design associated with a mathematical model allows determining the most influential compound in the mixtures (here, CLD). The present work, even if it is limited to a mixture of two products, suggests that the hydrochlordecones generated by remediation processes such as the ISCR do not appear to be more toxic than the CLD itself, and especially that their presence next to the CLD, at least for the concentrations expected to be found in the environment, does not increase the noxiousness compared to the baseline situation where CLD is alone. This is good news for the application of remediation processes unable to mineralize CLD and which will just lead to its transformation into dechlorinated products having conserved the bishomocubane structure. Further studies with more complex mixtures, representing more adequately those generated by such processes, remain however necessary to confirm their harmlessness.

\section{Declarations}

\section{Ethical Approval}

The present manuscript is an original study and was not submitted elsewhere in any form or language but some results were presented at the congress of the French Research Group on Pesticides (May 20th, 2021; http://www.gfpesticides.org/congres/579/593-20-mai-2021.html, in French) in the form of a commented slideshow (http://gfpesticides.org/uploads/video/J1V11-De-Jong-Moreau.mp4).

\section{Consent to Participate}

All authors agreed with the content and gave their explicit consent to submit the manuscript. They obtained consent from their Research lab and University where the work has been carried out.

\section{Authors Contributions}

Laetitia De Jong and Xavier Moreau contributed to the study overall conception and design and performed most of the exposure experiments with the help of Jean-Pascal Andraud. Magalie ClaeysBruno and Michelle Sergent contributed to the design of the experimental matrix and the development of the mathematical model. Daniel E Martínez performed the phylogenetic analysis of IMBE1 hydra clone. Hervé Macarie contributed to the selection of (1) the CLD dechlorinated product to be used for the study and (2) the range of concentrations of CLD and CLD-3Cl which are representative of the French West 
Indies environments. He also contributed to literature search, reconstruction of IMBE1 hydra clone lab history and to the analysis of the CLD-3Cl mass spectra to identify the possible isomers. Maxime Robin synthesized the CLD standard used in the study. All authors contributed to the analysis of the results. The first draft of the manuscript was written by Laetitia de Jong and Xavier Moreau and all authors commented on previous versions of the manuscript. All authors read and approved the final manuscript.

\section{Competing Interests}

The authors have no relevant financial or non-financial interests to disclose.

\section{Funding}

Partial funding for this work was provided by the European Regional Development Fund (FEDER) through the RIVAGE project (MQ0003772-CIRAD) and by an internal grant of IMBE research unit for stimulating cooperation between several of its constitutive teams. JPA was supported by a PhD grant from the ED251 doctoral school on Environmental Sciences of Aix Marseille University.

\section{Availability of data and materials}

Not applicable

\section{Acknowledgments}

Partial funding for this work was provided by the European Regional Development Fund (FEDER) through the RIVAGE project (MQ0003772-CIRAD) and by an internal grant of IMBE research unit for stimulating cooperation between several of its constitutive teams. JPA was supported by a PhD grant from the ED251 doctoral school on Environmental Sciences of Aix Marseille University. We thank Stéphane Greff from IMBE, Marseille, France, for his help in the analysis of the CLD-3Cl electronic impact mass spectra and Christian Blaise (Environment Canada), Sophie Pachura (Agestra, France) and Paule Vasseur (Université de Lorraine, France) for their help in reconstructing the laboratory historical use of strain IMBE1. Thanks to our students, Margot Cardenas-Saavedra, Estelle Levert, Nicolas Martin, Elisa Viande and Gaëlle Zanzana who have performed some of the exposure experiments during their laboratory internship.

\section{References}

1. Akaike H (1987) Factor analysis and AIC. Psychometrika 52: 317-332. https://doi.org/10.1007/9781-4612-1694-0_29

2. Alibrahim EA, Legeay S, Billat PA, Bichon E, Guiffard I, Antignac JP, Legras P, Roux J, Bristeau S, Clere $N$, Faure S, Mouvet $C$ (2020) In vivo comparison of the proangiogenic properties of chlordecone and three of its dechlorinated derivatives formed by in situ chemical reduction. Environ Sci Pollut Res 27:40953-40962. https://doi.org/10.1007/s11356-019-04353-5 
3. Arqué A, Bocaly M (2020) Suivi des produits phytopharmaceutiques dans les cours d'eau de Martinique / Following of phytosanitary products in the rivers of Martinique. Final Report, Office de l'eau Martinique, France. https://www.observatoire-eau-martinique.fr/documents/ODE972-Rapportpesticides-2019-VF.pdf (last access 29th November 2021)

4. Benoit P, Mamy L, Servien R, Li Z, Latrille E, Rossard V, Bessac F, Patureau D, Martin-Laurent F (2017) Categorizing chlordecone potential degradation products to explore their environmental fate. Sci Total Environ 574:781-795. https://doi.org/10.1016/j.scitotenv.2016.09.094

5. Blaise C, Gagné F, Harwood M, Quinn B, Hanana H (2018) Ecotoxicity responses of the freshwater cnidarian Hydra attenuata to 11 rare earth elements. Ecotoxicol Environ Saf 163:486-491. https://doi.org/10.1016/j.ecoenv.2018.07.033

6. Blaise C, Kusui T (1997) Acute toxicity assessment of industrial effluents with a microplate-based Hydra attenuata assay. Environ Toxicol Water Qual 12:53-60. https://doi.org/10.1002/(SICl)10982256(1997)12:1<53::AID-TOX8>3.0.C0;2-7

7. Bowden HC, Wilby OK, Botham CA, Adam PJ, Ross FW (1995) Assessment of the toxic and potential teratogenic effects of four glycol ethers and two derivatives using the hydra regeneration assay and rat whole embryo. Toxicol Vitro 9:773-781. https://doi.org/10.1016/0887-2333(95)00054-C

8. Box GEP, Hunter JS (1954) The study and exploitation of response regions. Biometrics 10:16-60. https://doi.org/10.2307/3001663

9. Box GEP, Hunter JS (1957) Multi-factor experimental designs for exploring response surfaces. Ann Math Stat 28:195-241. https://doi.org/10.1214/aoms/1177707047

10. Brown KA, Mays T, Romoser A, Marroquin-Cardona A, Mitchell NJ, Elmore SE, Phillips TD (2014) Modified hydra bioassay to evaluate the toxicity of multiple mycotoxins and predict the detoxification efficacy of a clay-based sorbent. J Appl Toxicol 34:40-48. https://doi.org/10.1002/jat.2824

11. Cabidoche YM, Achard R, Cattan P, Clermont-Dauphin C, Massat F, Sansoulet J (2009) Long-term pollution by chlordecone of tropical volcanic soils in the French West Indies: A simple leaching model accounts for current residue. Environ Pollut 157:1697-1705. https://doi.org/10.1016/j.envpol.2008.12.015

12. Cabidoche YM, Lesueur-Jannoyer M (2012) Contamination of harvested organs in root crops grown on chlordecone-polluted soils. Pedosphere 22:562-571. https://doi.org/10.1016/S10020160(12)60041-1

13. Campbell RD (1989) Taxonomy of the European Hydra (Cnidaria: Hydrozoa): a re-examination of its history with emphasis on the species $H$. vulgaris Pallas, $H$. attenuata Pallas and $H$. circumcincta Schulze. Zool J Linn Soc 95:219-244. https://doi.org/10.1111/j.1096-3642.1998.tb01992.x

14. Cannon SB, Veazey JM, Jackson RS, Burse VW, Hayes C, Straub WE, Landrigan PJ, Liddle JA (1978) Epidemic kepone poisoning in chemical workers. Am J Epidemiol 107:529-537. https://doi.org/10.1093/oxfordjournals.aje.a112572 
15. Cattan P, Charlier JB, Clostre F, Letourmy P, Arnaud L, Gresser J, Jannoyer M (2019) A conceptual model of organochlorine fate from a combined analysis of spatial and mid- to long-term trends of surface and ground water contamination in tropical areas (FWI). Hydrol Earth Syst Sci 23:691-709. https://doi.org/10.5194/hess-23-691-2019

16. Chevallier ML, Della-Negra O, Chaussonnerie S, Barbance A, Muselet D, Lagarde F, Darii E, Ugarte E, Lescop E, Fonknechten N, Weissenbach J, Woignier T, Gallard JF, Vuilleumier S, Imfeld G, Le Paslier D, Saaidi PL (2019) Natural chlordecone degradation revealed by numerous transformation products characterized in key French West Indies environmental compartments. Environ Sci Technol 53:61336143. https://doi.org/10.1021/acs.est.8b06305

17. Clostre F, Lesueur-Jannoyer M, Achard R, Letourmy P, Cabidoche YM, Cattan P (2014a) Decision support tool for soil sampling of heterogeneous pesticide (chlordecone) pollution. Environ Sci Pollut Res 21:1980-1992. https://doi.org/10.1007/s11356-013-2095-x

18. Clostre F, Woignier T, Rangon L, Fernandes P, Soler A, Lesueur-Jannoyer M (2014b) Field validation of chlordecone soil sequestration by organic matter addition. J Soils Sediments 14:23-33. https://doi.org/10.1007/s11368-013-0790-3

19. Coat S, Monti D, Legendre P, Bouchon C, Massat F, Lepoint G (2011) Organochlorine pollution in tropical rivers (Guadeloupe): Role of ecological factors in food web bioaccumulation. Environ Pollut 159:1692-1701. https://doi.org/10.1016/j.envpol.2011.02.036

20. Colpaert R, Villard P-H, De Jong L, Mambert M, Benbrahim K, Abraldes J, Cerini C, Pique V, Robin M, Moreau X (2020) Multi-scale impact of chronic exposure to environmental concentrations of chlordecone in freshwater cnidarian, Hydra circumcincta. Environ Sci Pollut Res 27:41052-41062. https://doi.org/10.1007/s11356-019-06859-4

21. Crabit A, Cattan P, Colin F, Voltz M (2016) Soil and river contamination patterns of chlordecone in a tropical volcanic catchment in the French West Indies (Guadeloupe). Environ Pollut 212:615-626. https://doi.org/10.1016/j.envpol.2016.02.055

22. Dawson GW, Weimer WC, Shupe SJ (1979) Kepone - a case study of a persistent material. AIChE Symposium series, $75, n^{\circ} 190$, pp. 366-374

23. De Jong L, Diana C, Campos JR, Arnoux A, Pellegrini L (1994) Toxicity of methyl mercury and mercury (II) chloride to a brown alga Cystoseira barbata (Fucales) under laboratory culture conditions. Detoxifying role of calcium. Bot Mar 37:367-379.

https://doi.org/10.1515/botm.1994.37.4.367

24. De Jong L, Pech N, De Aragão Umbuzeiro G, Moreau X (2016) Multi-scale biomarker evaluation of the toxicity of a commercial azo dye (Disperse Red 1) in an animal model, the freshwater cnidarian Hydra attenuata. Water Res 96:62-73. https://doi.org/10.1016/j.watres.2016.03.043

25. Dereumeaux C, Saoudi A, Guldner L, Pecheux M, Chesneau J, Thomé JP, Ledrans M, Le Tertre A, Denys S, Fillol C (2020) Chlordecone and organochlorine compound levels in the French West Indies population in 2013-2014. Environ Sci Pollut Res 27:41033-41045. https://doi.org/10.1007/s11356019-07181-9 
26. Devault DA, Laplanche C, Pascaline H, Bristeau S, Mouvet C, Macarie H (2016) Natural transformation of chlordecone into 5b-hydrochlordecone in French West Indies soils: statistical evidence for investigating long-term persistence of organic pollutants. Environ Sci Pollut Res 23:8197. https://doi.org/10.1007/s11356-015-4865-0

27. Dilling WL, Dilling ML (1967) Pentacyclodecane chemistry - III: Fragmentation patterns of pentacyclodecane derivatives on electron impact. Tetrahedron 23:1225-1233. https://doi.org/10.1016/0040-4020(67)85072-5

28. Dolfing J, Novak I, Archelas A, Macarie H (2012) Gibbs free energy of formation of chlordecone and potential degradation products: Implications for remediation strategies and environmental fate. Environ Sci Technol 46:8131-8139. https://doi.org/10.1021/es301165p

29. Droesbeke JJ, Fine J, Saporta G (1997) Plans d'expériences - Applications à l'entreprise / Experimental design - Business applications. Technip Edition. https://hal-cnam.archivesouvertes.fr/hal-02521474 (in French)

30. Dromard CR, Devault DA, Bouchon-Navaro Y, Allénou JP, Budzinski H, Cordonnier S, Tapie N, Reynal L, Lemoine S, Thomé JP, Thouard E, Monti D, Bouchon C (2019) Environmental fate of chlordecone in coastal habitats: recent studies conducted in Guadeloupe and Martinique (Lesser Antilles). Environ Sci Pollut Res 1-10. https://doi.org/10.1007/s11356-019-04661-w

31. Dyc C, Covaci A, Debier C, Leroy C, Delcroix E, Thomé JP, Das K (2015) Pollutant exposure in green and hawksbill marine turtles from the Caribbean region. Reg Stud Mar Sci 2:158-170. https://doi.org/10.1016/j.rsma.2015.09.004

32. Epstein SS (1978) Kepone-hazard evaluation. Sci Total Environ 9:1-62. https://doi.org/10.1016/0048-9697(78)90002-5

33. Filali-Meknassi Y, Tyagi RD, Surampalli RY, Barata C, Riva MC (2004) Endocrine-disrupting compounds in wastewater, sludge-treatment processes, and receiving waters: overview. Pract Period Hazard Toxic Radioact Waste Manag 8:39-56. https://doi.org/10.1061/(ASCE)1090025X(2004)8:1(39)

34. Gaume B, Dodet N, Thomé JP, Lemoine S (2015) Expression of biotransformation and oxidative stress genes in the giant freshwater prawn Macrobrachium rosenbergii exposed to chlordecone. Environ Sci Pollut Res 22:7991-8002. https://doi.org/10.1007/s11356-014-3134-y

35. Gore AC, Chappell VA, Fenton SE, Flaws JA, Nadal A, Prins GS, Toppari J, Zoeller RT (2015) EDC-2: the Endocrine Society's second scientific statement on endocrine-disrupting chemicals. Endocr Rev 36:E1-E150. https://doi.org/10.1210/er.2015-1010

36. Greco WR, Bravo G, Parsons JC (1995) The search for synergy: a critical review from a response surface perspective. Pharmacol Rev 47:331-385. PMID: 7568331

37. Guindon S, Dufayard JF, Lefort V, Anisimova M, Hordijk W, Gascuel O (2010) New algorithms and methods to estimate maximum likelihood phylogenies: assessing the performance of PhyML 3.0. Syst Biol 59:307-321. https://doi.org/10.1093/sysbio/syq010 
38. Hasegawa M, Kishino H, Yano T (1985) Dating the human-ape splitting by a molecular clock of mitochondrial DNA. J Mol Evol 22:160-174. https://doi.org/10.1007/BF02101694

39. Hoang DT, Chernomor O, von Haeseler A, Minh BQ, Vinh LS (2018) UFBoot2: Improving the ultrafast bootstrap approximation. Mol Biol Evol 35:518-522. https://doi.org/10.1093/molbev/msx281

40. Johnson EM (1980) A subvertebrate system for a rapid determination of potential teratogenic hazards. J Environ Pathol Toxicol 4:153-156. PMID: 7217843

41. Johnson EM, Gabel BE (1983) An artificial 'embryo' for detection of abnormal developmental biology. Fund Appl Toxicol 3:243-249. https://doi.org/10.1016/S0272-0590(83)80135-3

42. Johnson EM, Gorman RM, Gabel BE, George ME (1982) The Hydra attenuata system for detection of teratogenic hazards. Teratog Carcinog Mutagen 2:263-276. https://doi.org/10.1002/15206866(1990)2:3/4<263::AID-TCM1770020308>3.0.C0;2-I

43. Jondreville C, Lavigne A, Jurjanz S, Dalibard C, Liabeuf JM, Clostre F, Lesueur-Jannoyer M (2014) Contamination of free-range ducks by chlordecone in Martinique (French West Indies): A field study. Sci Total Environ 493:336-341. https://doi.org/10.1016/j.scitotenv.2014.05.083

44. Lavison-Bompard G, Parinet J, Huby K, Guérin T, Inthavong C, Lambert M (2021) Correlation between endemic chlordecone concentrations in three bovine tissues determined by isotopic dilution liquid chromatography-tandem mass spectrometry. Sci Total Environ 788:147833. https://doi.org/10.1016/j.scitotenv.2021.147833

45. Le Déaut J-Y, Procaccia C (2009) Pesticide use in the Antilles: current situation and perspectives for change. OPECST report n 487 (2008-2009). French Senat. ISBN: 9782111267688, http://www.senat.fr/rap/r08-487/r08-4871.pdf (in French)

46. Legeay S, Billat PA, Clerel N, Nesslany F, Bristeau S, Faure S, Mouvet C (2017) Two dechlorinated chlordecone derivatives formed by in situ chemical reduction are devoid of genotoxicity and mutagenicity and have lower proangiogenic properties compared to the parent compound. Environ Sci Pollut Res 25:14313-14323. https://doi.org/10.1007/s11356-017-8592-6

47. Lesueur-Jannoyer M, Mottes C, Clostre F, Carles C, Guene M, Plet J, Della Rossa P, Bazizi A, Cattan P (2016) Characterization of river pollution at the watershed scale. In: Lesueur Jannoyer M, Cattan P, Woignier T, Clostre $\mathrm{F}$ (Eds.) Crisis management of chronic pollution: Contaminated soil and human health, CRC Press, Boca Raton, USA, pp 45-54

48. Liber Y, Létondor $C$, Pascal-Lorber S, Laurent $F$ (2018) Growth parameters influencing uptake of chlordecone by Miscanthus species. Sci Total Environ 624:831-837. https://doi.org/10.1016/j.scitotenv.2017.12.071

49. Lomheim L, Laquitaine L, Rambinaising S, Flick R, Starostine A, Jean-Marius C, Edwards EA, Gaspard $S$ (2020) Evidence for extensive anaerobic dechlorination and transformation of the pesticide chlordecone $\left(\mathrm{C}_{10} \mathrm{Cl}_{10} \mathrm{O}\right)$ by indigenous microbes in microcosms from Guadeloupe soil. PloS one 15:e0231219. https://doi.org/10.1371/journal.pone.0231219

50. Macarie H, Novak I, Sastre-Conde I, Labrousse Y, Archelas A, Dolfing J (2016) Theoretical approach of chlordecone biodegradation. In: Lesueur Jannoyer M, Cattan P, Woignier T, Clostre F (Eds.) Crisis 
management of chronic pollution: Contaminated soil and human health, CRC Press, Boca Raton, USA, pp. 191-209. https://hal.ird.fr/ird-01559694v3

51. Macaulay SJ, Hageman KJ, Piggott JJ, Matthaei CD (2021) Imidacloprid dominates the combined toxicities of neonicotinoid mixtures to stream mayfly nymphs. Sci Total Environ 761:143263. https://doi.org/10.1016/j.scitotenv.2020.143263

52. Martin O, Scholze M, Ermler S, McPhie J , Bopp SK, Kienzler A, Parissis N, Kortenkamp A (2021) Ten years of research on synergisms and antagonisms in chemical mixtures: A systematic review and quantitative reappraisal of mixture studies. Environ Int 146:106206. https://doi.org/10.1016/j.envint.2020.106206

53. Martínez DE, Iñiguez AR, Percell KM, Willner JB, Signorovitch J, Campbell RD (2010) Phylogeny and biogeography of Hydra (Cnidaria: Hydridae) using mitochondrial and nuclear DNA sequences. Mol Phylogenet Evol 57:403-410. https://doi.org/10.1016/j.ympev.2010.06.016

54. Mathieu-Denoncourt J, Wallace SJ, de Solla SR, Langlois VS (2015) Plasticizer endocrine disruption: Highlighting developmental and reproductive effects in mammals and non-mammalian aquatic species. Gen Comp Endocrinol 219:74-88. https://doi.org/10.1016/j.ygcen.2014.11.003

55. Méndez-Fernandez P, Kiszka JJ, Heithaus MR, Beal A, Vandersarren G, Caurant F, Spitz J, Taniguchi S, Montone RC (2018) From banana fields to the deep blue: Assessment of chlordecone contamination of oceanic cetaceans in the eastern Caribbean. Mar Pollut Bull 137:56-60. https://doi.org/10.1016/j.marpolbul.2018.10.012

56. Mottes C, Lesueur Jannoyer M, Le Bail M, Guéné M, Carles C, Malézieux E (2017) Relationships between past and present pesticide applications and pollution at a watershed outlet: The case of a horticultural catchment in Martinique, French West Indies. Chemosphere. 184:762773. https://doi.org/10.1016/j.chemosphere.2017.06.061

57. Mottes C, Deffontaines L, Charlier JB, Comte I, Della Rossa P, Lesueur-Jannoyer M, Woignier T, Adele G, Tailame AL, Arnaud L, Plet J, Rangon L, Bricquet JP, Cattan P (2020) Spatio-temporal variability of water pollution by chlordecone at the watershed scale: what insights for the management of polluted territories? Environ Sci Pollut Res 27:40999-41013. https://doi.org/10.1007/s11356-019-06247-y

58. Mouvet C, Collet B, Gaude JM, Rangon L, Bristeau S, Senergues M, Lesueur-Jannoyer M, Jestin A, Hellal J, Woignier T (2020) Physico-chemical and agronomic results of soil remediation by In Situ Chemical Reduction applied to a chlordecone-contaminated nitisol at plot scale in a French Caribbean banana plantation. Environ Sci Pollut Res 27:41063-41092. https://doi.org/10.1007/s11356-020-07603-z

59. Mouvet C, Dictor MC, Bristeau S, Breeze D, Mercier A (2017) Remediation by chemical reduction in laboratory mesocosms of three chlordecone-contaminated tropical soils. Environ Sci Pollut Res 24:25500-25512. https://doi.org/10.1007/s11356-016-7582-4

60. Multigner L, Kadhel P, Rouget F, Blanchet P, Cordier S (2016) Chlordecone exposure and adverse effects in French West Indies populations. Environ Sci Pollut Res 23:3-8. https://doi.org/10.1007/s11356-015-4621-5 
61. Nguyen LT, Schmidt HA, von Haeseler A, Minh BQ (2015) IQ-TREE: A fast and effective stochastic algorithm for estimating maximum likelihood phylogenies. Mol Biol Evol 32:268-274. https://doi.org/10.1093/molbev/msu300

62. Nørgaard KB, Cedergreen N (2010) Pesticide cocktails can interact synergistically on aquatic crustaceans. Environ Sci Pollut Res 17:957-967. https://doi.org/10.1007/s11356-009-0284-4

63. Ollivier P, Engevin J, Bristeau S, Mouvet C (2020a) Laboratory study on the mobility of chlordecone and seven of its transformation products formed by chemical reduction in nitisol lysimeters of a banana plantation in Martinique (French Caribbean). Sci Total Environ 743:140757. https://doi.org/10.1016/j.scitotenv.2020.140757

64. Ollivier P, Touzelet S, Bristeau S, Mouvet C (2020b) Transport of chlordecone and two of its derivatives through a saturated nitisol column (Martinique, France). Sci Total Environ 704:135348. https://doi.org/10.1016/j.scitotenv.2019.135348

65. Pachura-Bouchet S (2005) Toxicité et effets sur le développement d'Hydra attenuata des polluants hydriques et du nonylphénol (NP) / Toxicity and effect on Hydra attenuata development of hydric pollutants and nonylphenol (NP). PhD dissertation, Université Paul-Verlaine, Metz, France. https://hal.univ-lorraine.fr/tel-01752396/document (in French)

66. Pachura-Bouchet S, Blaise C, Vasseur P (2006) Toxicity of nonylphenol on the cnidarian Hydra attenuata and environmental risk assessment. Environ Toxicol 21:388-394. https://doi.org/10.1002/tox.20201

67. Pachura S, Cambon JC, Blaise C, Vasseur P (2005) 4-nonylphenol induced toxicity and apoptosis in Hydra attenuata. Env Toxicol Chem, 24:3085-3091. https://doi.org/10.1897/04-669r.1

68. Park HG, Yeo MK (2012) The toxicity of triclosan, bisphenol A, bisphenol A diglycidylether to the regeneration of cnidarian, Hydra magnipapillata. Mol Cell Toxicol 8:209-216. https://doi.org/10.1007/s13273-012-0026-4

69. Posada D (2008) jModelTest: phylogenetic model averaging. Mol Biol Evol 25:1253-1256. https://doi.org/10.1093/molbev/msn083

70. Quinn B, Gagné F, Blaise C (2008) The effects of pharmaceuticals on the regeneration of the cnidarian, Hydra attenuata. Sci Total Environ 402:62-69. https://doi.org/10.1016/j.scitotenv.2008.04.039

71. Rambaut A (2009) FigTree. [Online]. Available: tree.bio.ed.ac.uk/software/figtree/ [2021, Oct 25]

72. Ranguin R, Jean-Marius C, Yacou C, Gaspard S, Delannoy M (2020) Reduction of chlordecone environmental availability by soil amendment of biochars and activated carbons from lignocellulosic biomass. Environ Sci Pollut Res 27:41093-41104. https://doi.org/10.1007/s11356-019-07366-2

73. Sabatier P, Mottes C, Cottin N, Evrard O, Comte I, Piot C, Gay B, Arnaud F, Lefevre I, Develle AL, Deffontaines L, Plet J, Lesueur-Jannoyer M, Poulenard J (2021) Evidence of chlordecone resurrection by glyphosate in French West Indies. Environ Sci Technol 55:2296-2306. https://dx.doi.org/10.1021/acs.est.0c05207 
74. Sarabia LA, Ortiz MC (2009) Response surface methodology. In: Brown SD, Tauler R, Walczak B (Eds.) Comprehensive Chemometrics, Elsevier, Oxford, UK, pp. 251-300. https://doi.org/10.1016/B978-044452701-1.00083-1

75. Sørensen H, Cedergreen N, Skovgaard I, Streibig JC (2007) An isobole based statistical model and test for synergism/antagonism in binary mixture toxicity experiments. Environ Ecol Stat 14:383-397 https://doi.org/10.1007/s10651-007-0022-3

76. Swofford DL (2003) PAUP*. Phylogenetic Analysis Using Parsimony (*and Other Methods). Version 3. Sinauer Associates, Sunderland, Massachusetts.

77. Tarrant AM (2005) Endocrine-like signaling in cnidarians: Current understanding and implications for ecophysiology. Integr Comp Biol 45:201-214. https://doi.org/10.1093/icb/45.1.201

78. Trottier S, Blaise C, Kusui T, Johnson EM (1997) Acute toxicity assessment of aqueous samples using a microplate-based Hydra attenuata assay. Environ Toxicol Water Qual 12:265-271. https://doi.org/10.1002/(SICI)1098-2256(1997)12:3<265::AID-TOX10>3.0.C0;2-9

79. Vandenberg LN, Colborn T, Hayes TB, Heindel JJ, Jacobs DR Jr, Lee DH, Shioda T, Soto AM, vomSaal FS, Welshons WV, Zoeller RT, Myers JP (2012) Hormones and endocrine-disrupting chemicals: Lowdose effects and nonmonotonic dose responses. Endocr Rev 33:378-455. https://doi.org/10.1210/er.2011-1050

80. Vasseur P, Pachura S (2006) Le modèle « Hydre » pour l'évaluation de l'impact sur l'environnement / The hydra model for evaluating environmental impact. Environ Risques St 5:280-283. (In French)

81. Wilby OK, Tesh JM (1990) The Hydra assay as an early screen for teratogenic potential. Toxicol Vitro 4:582-583. https://doi.org/10.1016/0887-2333(90)90119-E

82. Yang G, Chen C, Wang Y, Peng Q, Zhao H, Guo D, Wang Q, Qian Y (2017) Mixture toxicity of four commonly used pesticides at different effect levels to the epigeic earthworm, Eisenia fetida. Ecotoxicol Environ Saf 142:29-39. https://doi.org/10.1016/j.ecoenv.2017.03.037

83. Zwickl DJ (2006) Genetic algorithm approaches for the phylogenetic analysis of large biological sequence datasets under the maximum likelihood criterion. PhD dissertation, University of Texas, Austin.

\section{Figures}

\section{Figure 1}

Stereomicroscopic pictures. (a) Healthy and budding hydra polyp showing the level of two transverse sections (black lines). (b) The three parts of the polyp obtained after transverse sections. Only the central section of the hydra body, also called 'gastric region' ( $g r)$, is conserved for regeneration experiments. $b d$ : basal disc; $m$ : mouth; $t$. tentacle 


\section{Figure 2}

Synoptic diagram of the 18 experimental conditions chosen in the entire domain of studied concentrations. Rectangles represent the mixture conditions used for the composite design, ovals represent the mixtures of the validation points and stars represent the mixtures added to evaluate a possible endocrine impact. The exact concentration values for the 18 mixtures are summarized in table 3

\section{Figure 3}

GC-El-MS chromatogram of Alpha Chimica CLD-3Cl product (A) and corresponding mass spectra (B) provided by the furnisher. The structure of the CLD-3Cl isomers that can give such mass spectra after electronic impact are indicated on the right side of the figure

\section{Figure 4}

Rooted maximum likelihood phylogram generated using ITS1 and ITS2 regions of ribosomal DNA. The IMBE1 strain used in this study (arrow) is nested within a group of European Hydra vulgaris. Numbers on internal nodes represent bootstrap values calculated over 1000 pseudo replicates with three different methods: Maximum likelihood implemented using IQtree / Maximum Likelihood implemented using Garli / Neighbor Joining implemented using PAUP

\section{Figure 5}

Mean regeneration scores in the experimental range of tested CLD and CLD-3Cl concentrations. Horizontal central axis = CLD concentrations used in the experiments: concentrations increase from left to right. Vertical axis = CLD-3Cl concentrations of dechlorinated chlordecone: concentrations increase from bottom to top. The experimental domain is represented as a square that could be divided in four equal parts: left down and top squares for mixtures with low to medium CLD concentrations along a gradient of CLD-3Cl concentrations from low to high, right down and top squares for mixtures with medium to high CLD concentrations along a gradient of CLD-3Cl concentrations from low to high. Mean regeneration scores could be interpreted as follow: 0 to $1=$ death; 2 to $5.9=$ extremely toxic (black symbols); 6 to 6.9 =very toxic (black symbols); 7 to $7.9=$ toxic (grey symbols); 8 to $8.9=$ low toxicity, viable polyp (white symbols); 9 to $10=$ no toxicity, healthy polyp (white symbols). The disturbing scores are in white letters. For symbol significance, see figure 2 legend 


\section{Figure 6}

Modeling of hydra regeneration scores exposed to mixtures of CLD and CLD-3Cl within the experimental domain showing isoscore lines. Limits of experimental domain are $2.10^{-4} \mu \mathrm{M}$ and $4.10^{-2} \mu \mathrm{M}$ for both compounds. Mean regeneration scores could be interpreted as follow: 0 to $1=$ death; 2 to $5.9=$ extremely toxic; 6 to 6.9 =very toxic; 7 to $7.9=$ toxic; 8 to $8.9=$ low toxicity, viable polyp; 9 to $10=$ no toxicity, healthy polyp 